\title{
MLM-2277
}

\section{Internal Friction in Uranium}

\author{
J. E. Selle
}

November 20, 1975

Research and Development Report

\section{MOUND LABORATORY}

Miamisburg, Ohio

operated by

Monsanto

MONSANTO RESEARCH CORPORATION a subsidiary of Monsanto Company

for the

UNITED STATES ENERGY RESEARCH AND DEVELOPMENT ADMINISTRATION

U. S. Government Contract No. E-33-1-GEN-53 


\section{DISCLAIMER}

This report was prepared as an account of work sponsored by an agency of the United States Government. Neither the United States Government nor any agency Thereof, nor any of their employees, makes any warranty, express or implied, or assumes any legal liability or responsibility for the accuracy, completeness, or usefulness of any information, apparatus, product, or process disclosed, or represents that its use would not infringe privately owned rights. Reference herein to any specific commercial product, process, or service by trade name, trademark, manufacturer, or otherwise does not necessarily constitute or imply its endorsement, recommendation, or favoring by the United States Government or any agency thereof. The views and opinions of authors expressed herein do not necessarily state or reflect those of the United States Government or any agency thereof. 


\section{DISCLAIMER}

Portions of this document may be illegible in electronic image products. Images are produced from the best available original document. 


$\begin{aligned} & \text { MLM-2277 } \\ \text { DIstribution Category UC-25 } & \text { UID }-450 \\ & \end{aligned}$

\title{
Internal Friction in Uranium
}

\author{
J. E. Sel1e*
}

Issued: November 20,1975

*Presently at Oak Ridge National Laboratory

\section{NOTICE}

This report was prepared as an account of work sponsored by the United States Government. Neither the United States nor the United Statos Energy Research and Development Administration, nor any of their employees, nor eny of their contractors, subcontractors, or their employees, makes any warranty, express or implied, or assumes any legal llability or responsibility for the accuracy, completeness or usefulness of any information, apparatus, product or process disclosed or represents that its use would not infringe privately owned rights.

PRINTED IN THE UNITED STATES OF AMERICA

Available from

Netional Tećhnical Information Service

U. S. Department of Commerce 5285 Port. Royal Road

Springfield, Virginia 22161

Price: Printed Copy $\$ 4.00$; Microfiche $\$ \mathbf{2} .25$

\section{MONSANTO RESEARCH CORPORATION}

A Subsidiary of Monsanto Company

*.

\section{mOUnD IABORATORY}

Miamisburg. Ohio

45342

operated for

\section{UNITED STATES ENERGY RESEARCH AND DEVELOPMENT ADMINISTRATION}

U. S. Government Contract No. E-33-1-GEN-53 
TABLE OF CONTENTS

$\underline{\text { Page }}$

INTRODUCTION . . . . . . . . . . . . . . . . . . . . . . . . . . . 3

PROCEDURE . . . . . . . . . . . . . . . . . . . . . . . . . 3

RESULTS

GENERAL FEATURES

BACKGROUND INTERNAL FRICTION.$\cdot \cdot \cdot \cdot \cdot \cdot \cdot \cdot \cdot \cdot \cdot \cdot \cdot \cdot \cdot \cdot \cdot \cdot \cdot \cdot \cdot \cdot \quad 7$

GRAIN BOUNDARY RELAXATION . . . . . . . . . . . . . . . . . . . 14

DISCUSSION

GENERAL FEATURES . . . . . . . . . . . . . . . . . . . . . . 19

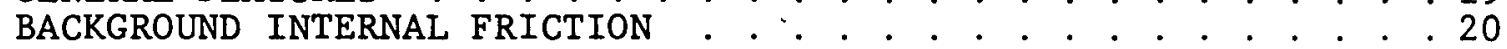

GRAIN BOUNDARY RELAXATION . . . . . . . . . . . . . . . . . . . 20

CONCLUSIONS .. . . . . . . . . . . . . . . . . . . . . . . . . 21

REFERENCES . . . . . . . . . . . . . . . . . . . . . . . . 23

APPENDIX . . . . . . . . . . . . . . . . . . . . . . . . . 24 


\section{INTRODUCTION}

The internal friction of uranium is of interest because of the need for information on the physical metallurgy of this metal. The present work was undertaken as part of a study intended to relate internal friction measurements to allotropic transformations. ${ }^{1}$ It was felt that information obtained during this work was of sufficient interest to merit further discussion.

Earlier work by Maringer et al. ${ }^{2}$ showed changes in internal friction as a result of changing heating and cooling rates. From this work, it was concluded that the various internal friction phenomena are the result of stress-induced motion of twin boundaries. Further work by Maringer ${ }^{3}$ showed peaks caused by stress-induced motion of twin boundaries, grain boundary relaxation, and at the $\alpha \rightarrow \beta$ transformation. Dashkovskii et al. ${ }^{4}$ also measured the internal friction of uranium and found that the internal friction in $\alpha$-uranium depends on the heat treatment and decreases after $\beta$ or $\gamma$ annealing. The internal friction was found to change isothermally during allotropic transformation, and each phase was found to have its own value of internal friction.

\section{PROCEDURE}

An inverted torsion pendulum, similar to that described by Wert, ${ }^{5}$ was used. The recording device consisted of two pairs of coils mounted at right angles to each other as shown in Figure 1 . A potential of about $4 \mathrm{~V}$ at $2500 \mathrm{~Hz}$ was applied to one pair of coils producing a magnetic field between them which, in turn, induced a small current in the second pair of coils. An iron blade attached to the inertial member cuts the magnetic field to a degree which depends on the position of the blade. As a result, the induced current in the second pair of coils changes with the position of the blade. The output of this second pair of coils is amplified and recorded on an oscillograph.

Maximum strain amplitudes of 1 to $5 \times 10^{-5}$ were used. The apparatus was evacuated to less than $1 \times 10^{-5} \mathrm{~mm} \mathrm{Hg}$.

The samples were 8 in. long by 0.040 in. in diameter.'Grain boundary relaxation studies were done with a single wire which had been heated to $738^{\circ} \mathrm{C}$ for $2 \mathrm{hr}$, cooled to $650^{\circ} \mathrm{C}$, held for $2 \mathrm{hr}$ at $650^{\circ} \mathrm{C}$, and then slowly cooled to room temperature. A preliminary run was then made to $635^{\circ} \mathrm{C}$. Measurements were made after an anneal at each temperature of from 1 to $3 \frac{1}{2} \mathrm{hr}$, depending on the temperature. The total time above $550^{\circ} \mathrm{C}$ on the preliminary run was $12 \mathrm{hr}$. This procedure was followed to avoid complications from varying grain size. After this preliminary run, three more runs were made at different frequencies; in the data to be presented, these determinations are labelled A, B, and C. Results obtained with other wires are labelled with numbers 1 to 5 . The maximum temperature for each of the grain boundary relaxation studies was $635^{\circ} \mathrm{C}$. An analysis of the grain boundary relaxation data was made according to the method described by Nowick and Berry. ${ }^{6}$ A more detailed description of this analysis is given in the Appendix. 


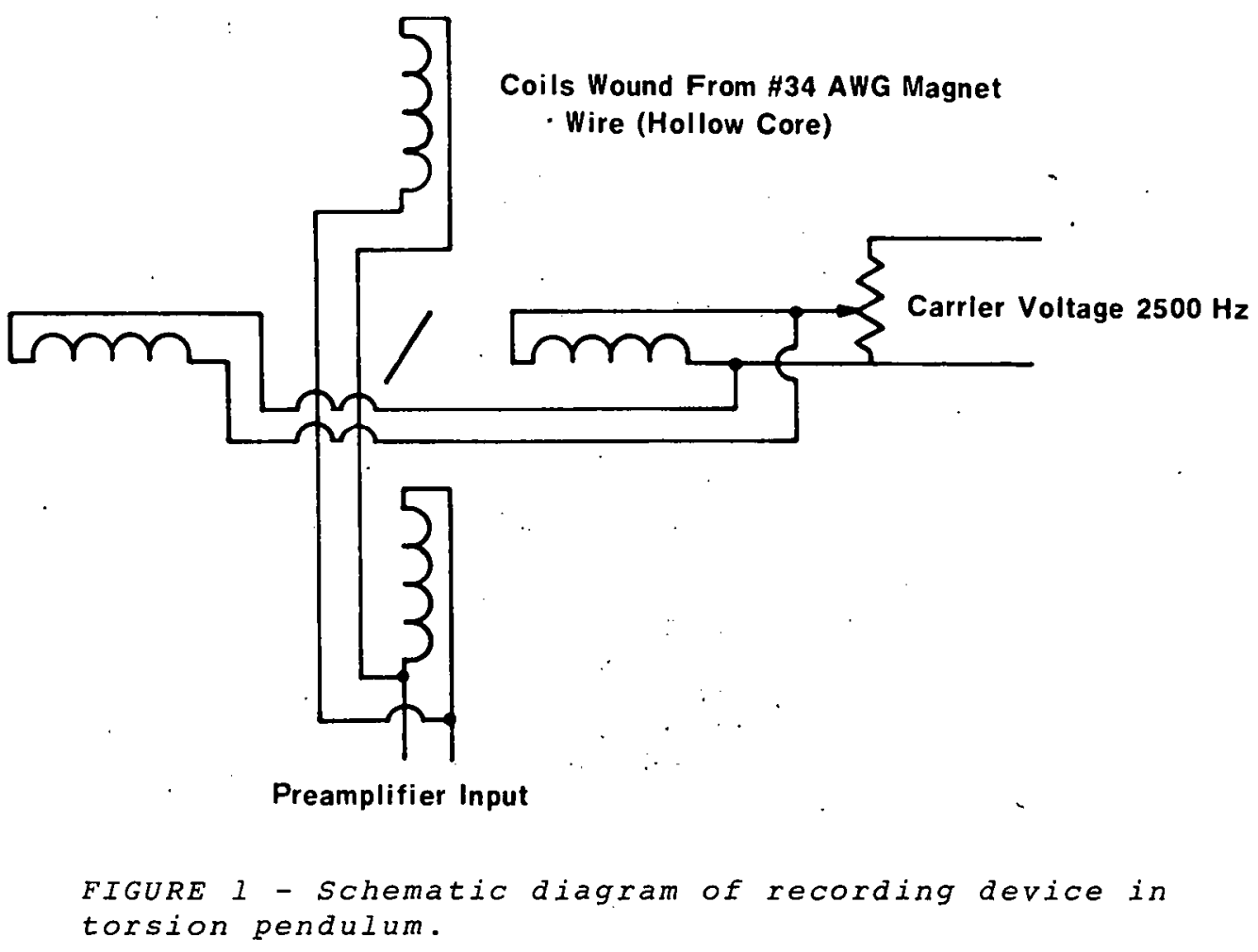

Annealing for 1 to $3 \frac{1}{2} \mathrm{hr}$ at each temperature was necessary because earlier work indicated that if uranium were not annealed long enough at measurement temperature, the value of internal friction was significantly greater than the value obtained if the annealing time were increased. The longer annealing times avoided errors from this source.

Spectrographic and chemical analyses are given in Table 1.

\section{RESULTS}

\section{GENERAL FEATURES}

A plot of internal friction as a function of temperature for $\alpha$-uranium annealed at $585^{\circ} \mathrm{C}$ is shown in Figure 2. Three major peaks are observed whose locations were found to change with frequency. A summary of peak temperature at various frequencies is given in Table 2. Activation energies calculated from these data are approximately 74 and $35 \mathrm{kcal} / \mathrm{mole}$ for the two lowest temperature peaks. The data show some scatter suggesting a dependence on some other factor such as grain size. The peak just below the $\alpha \rightarrow \beta$ transformation appears to be directly associated with the peak itself. An applied tensile stress of 200 psi was sufficient to lower the peak temperature from $635^{\prime}$ to $627^{\circ} \mathrm{C}$ at a frequency of about $1.75 \mathrm{~Hz}$. The activation energy is calculated to be about $37 \mathrm{kcal} / \mathrm{mole}$, again with some scatter in the data. 


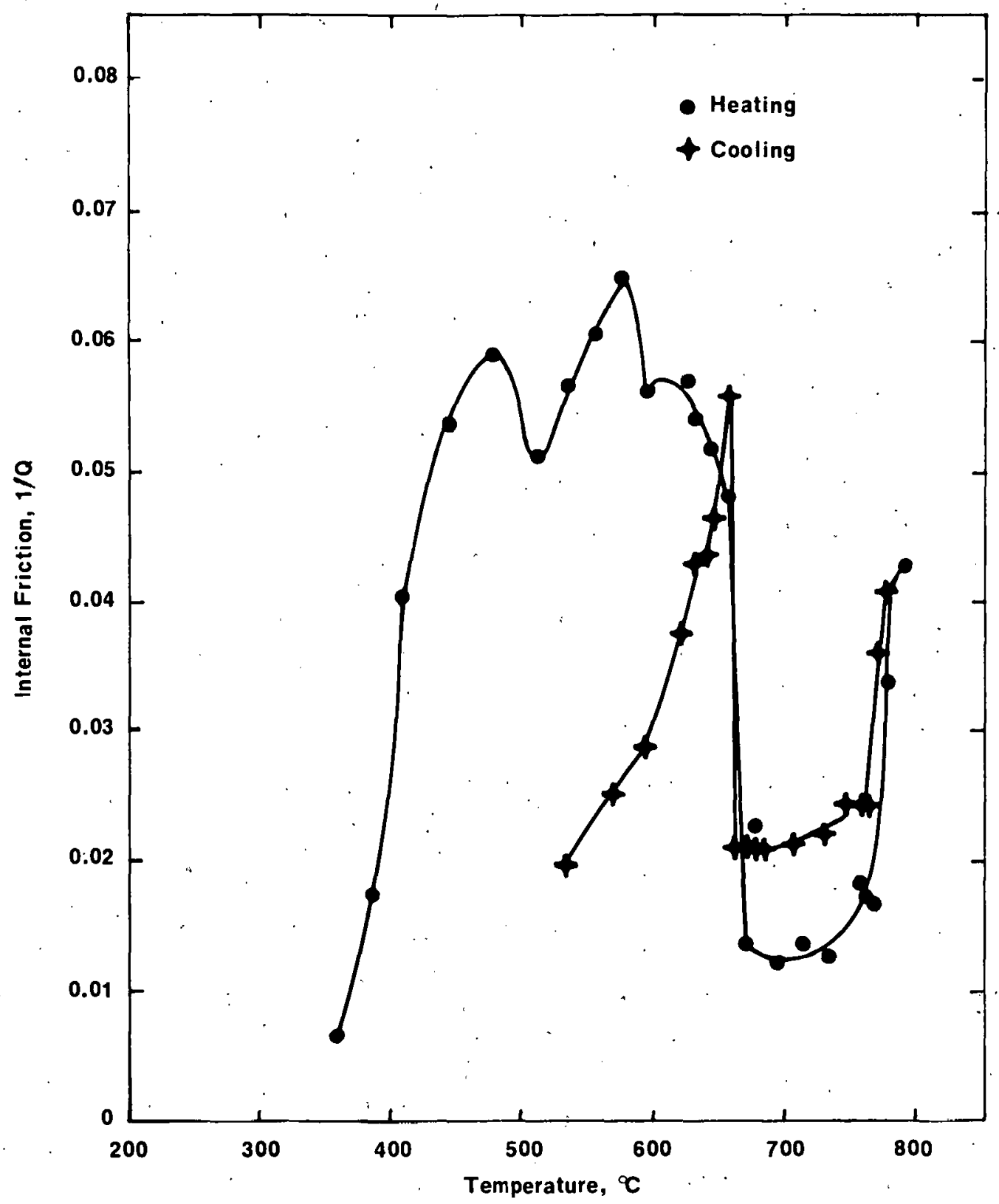

FIGURE. 2 - Internal friction of uranium as a function of temperature for $\alpha$-annealed uranium. 
Table 1

CHEMICAL AND SPECTROGRAPHIC ANALYSIS OF THE URANIUM WIRE

Spectrographic Analysis

Element

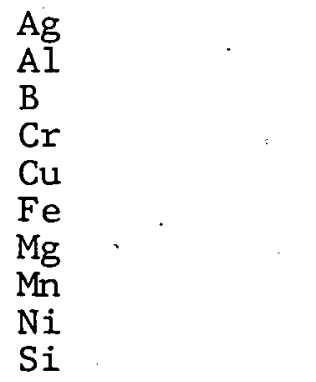

Chemical Analysis

C

$\mathrm{O}$
Analysis

(ppm)

0.4

20.0

0.2

13.0

11.0

150.0

4.0

5.0

40.0

95.0

390.0

100.0

30.0

Table 2

PEAK TEMPERATURES FOR FREQUENCIES FOR ALPHA URANIUM

Run 1 Temp. $1 \times 10^{3}$ Frequency Temp. Run 2

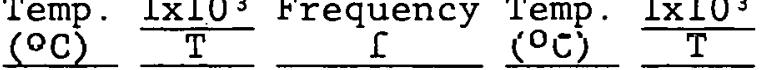

Peak Frequ

I

(low temp.)

$470 \quad 1.346$

1.261

4621.360

1.814

$475 \quad 1.338$

2.125

II

5751.180

1. 104

$596 \quad 1.151$

1.518

5951.151

1.855

III (high temp.

$614 \cdot 1.127$

1.084

$633 \quad 1.102$

1.487

$635 \cdot 1.101$

1.804 
Annealing in the $\beta$ phase gives an internal friction curve as shown in Figure 3. Several differences between this curve and Figure 2 are noted. The internal friction at the transformation temperature rises to a sharp peak in $\beta$-annealed material. This peak does not appear to be a relaxation peak, but only because of the maximum value of $\alpha$-uranium obtainable prior to transformation to $\beta$. There is only one other peak in the $\beta$-annealed sample whereas there are two peaks in $\alpha$-annealed material. This peak appears to be associated with grain boundary relaxation. The internal friction of $\beta$ formed from $\alpha$ is constant regardless of the condition of the $\alpha$ phase. Values for the relative shear modulus for both cases are given in Figure 4.

The internal frictions of the $\beta$ and $\gamma$ phases show less variation and less sensitivity to thermal treatment than does the $\alpha$ phase. This is shown in Figure 2 and 3 . While the $\beta$ phase formed from $\alpha$ shows little sensitivity to thermal treatment, the value of $\beta$ formed from $\gamma$ is considerably higher than $\beta$ formed from $\alpha$.

Isothermal transformation during the various transformations is shown in Figures 5 and 6 . It can be seen that the internal friction changes abruptly during the $\alpha \rightarrow \beta$ and $\beta \rightarrow \alpha$ transformations, but shows a maximum during the $\beta \rightarrow \gamma$ and $\gamma \rightarrow \beta$ transformations. However, in all cases, the internal friction charges isothermally during the transformations, in agreement with Dashkovskii et al. ${ }^{4}$.

\section{BACKGROUND INTERNAL FRICTION}

Results obtained at a room temperature frequency of $2.90 \mathrm{~Hz}$ are shown in Figure 7. The grain boundary peak, at about $520^{\circ} \mathrm{C}$, is very small and is partially masked by the background internal friction. Therefore, this background internal friction is quite important to any analysis of this peak and must be subtracted from the total internal friction in order to obtain a true peak. ${ }^{7}$ The procedure for this is quite simple and is based on the fact that the background internal friction increases exponentially with temperature and conforms to an equation of the form

$$
\frac{1}{\mathrm{Q}}=\frac{1}{\mathrm{Q}_{0}} e^{-\mathrm{H}^{*} \mathrm{BKG}} \mathrm{RT}
$$

where $1 / Q$ is the internal friction, $1 / Q_{0}$ is a constant, and $H^{*} B K G$ is an activation energy for the process. For this type of relationship a plot of $\log 1 / Q$ as a function of $1 / T$ should yield a straight line for the true background internal friction, whose slope equals $\mathrm{H}^{*} \mathrm{BKG} / \mathrm{R}$. When the data of Figure 7 are plotted in this manner, Figure 8 is obtained.

The background internal friction is indicated by the dotted line. The temperature of departure from the base line was relatively constant, for the eight determinations given, at about $6580 \mathrm{~K}\left(1 / \mathrm{T}=1.52 \times 10^{-3}\right)$. However, the background activation was found to be a function of the frequency at the grain houndary peak or. the room temperature frequency as shown in Figure 9. Data for runs $A, B$, and $C$ only are shown because ch1s relationship is extremely sensitive to sample treatment. Since the sample treatment affects the grain size, the terms "sample treatment" and "grain.size" will be used synonymously. Data points for runs 1 to 5 show considerable scatter from these lines. At the same time, a plot of $\mathrm{H}^{*} \mathrm{BKG}$ as a function of the reciprocal of the peak temperature, $1 / \mathrm{T}_{\mathrm{P}}$, yields 


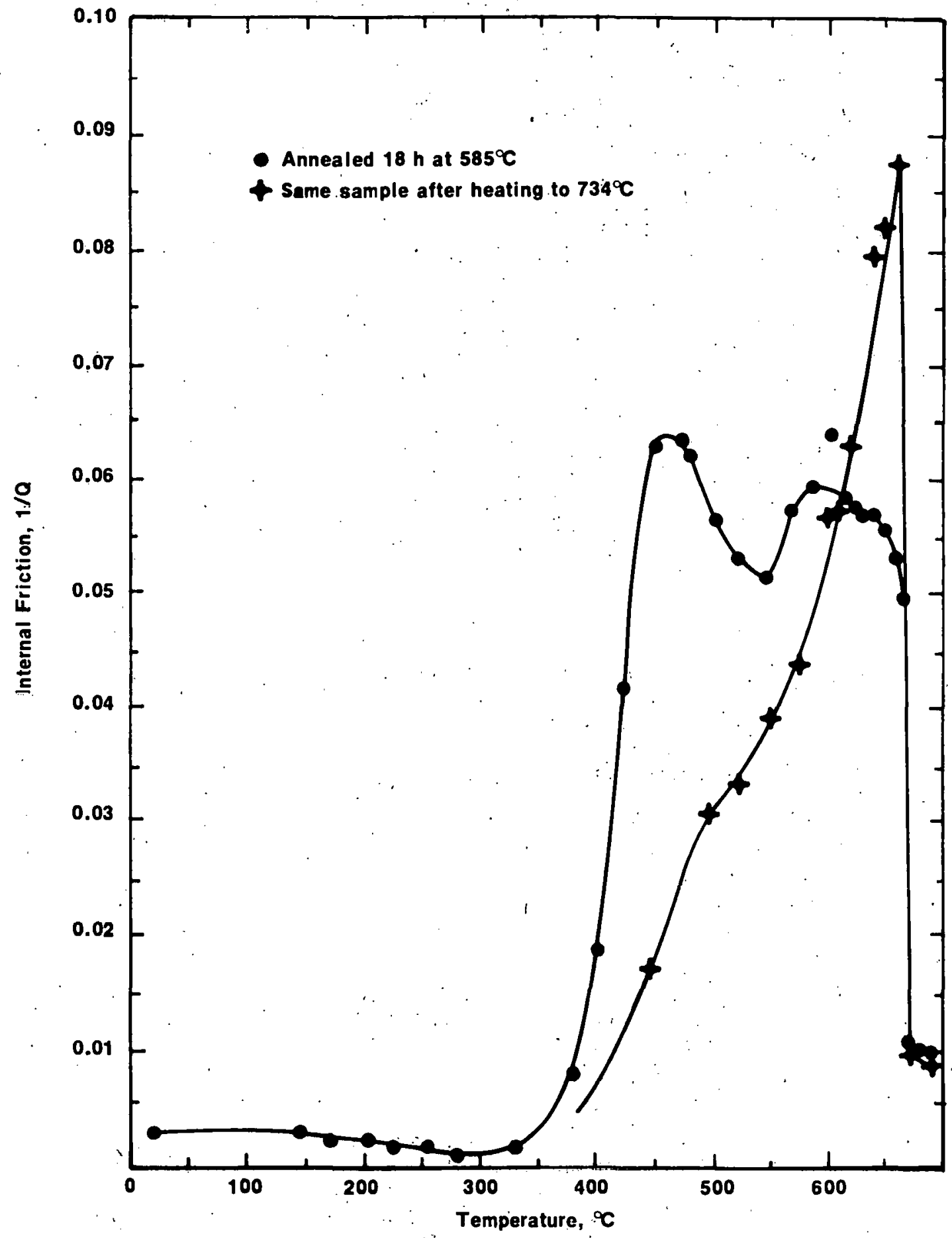

FIGURE 3 - Internal friction of $\alpha$-uranium for $\alpha$-annealed and B-annealed sample. 


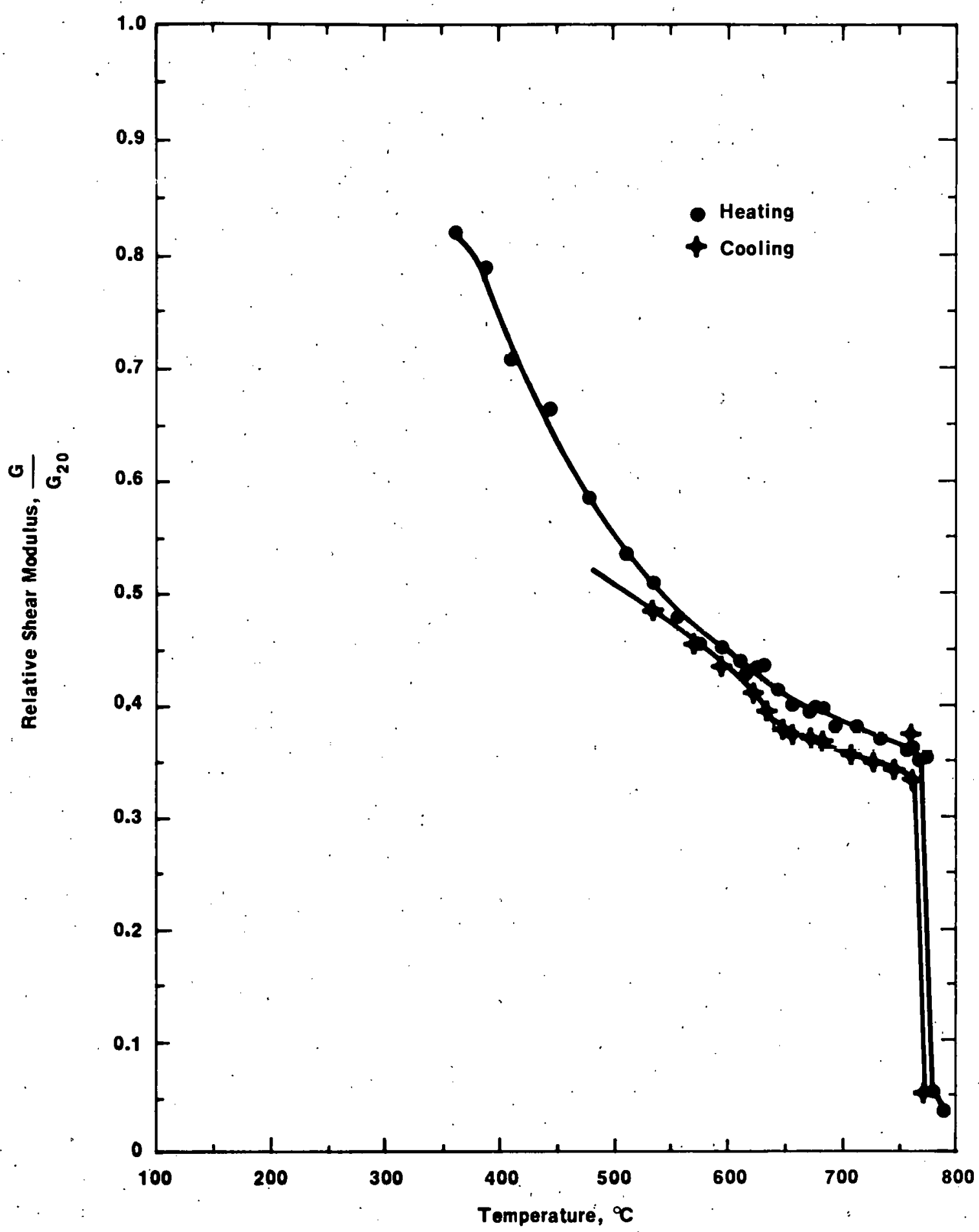

FIGURE - Relative shear modulus as a function of temperature. 


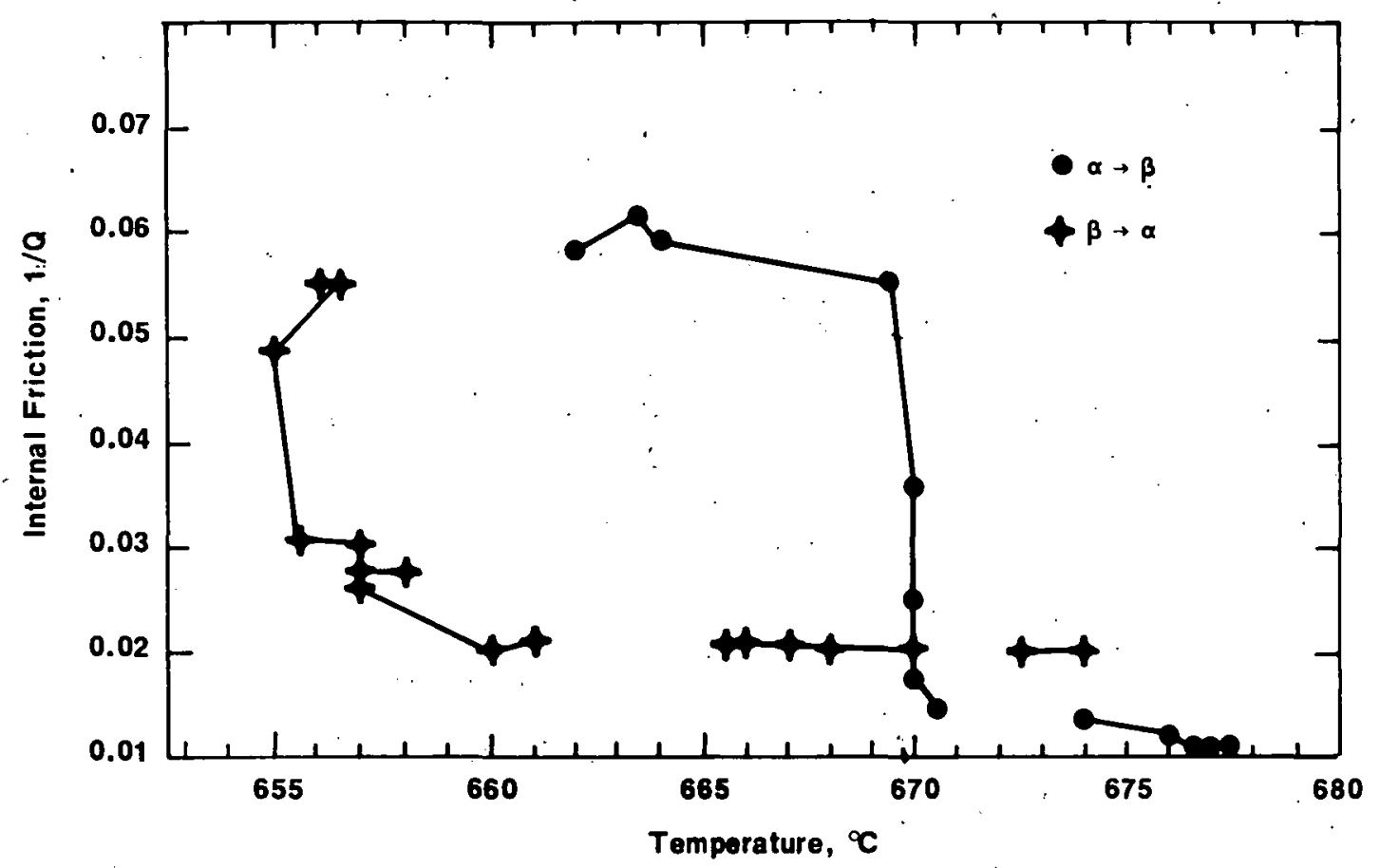

FIGURE 5 - Dynamic internal friction values measured during isothermal transformation of the $\alpha \rightarrow \beta$ and $\beta \rightarrow \alpha$ transformations of uranium.

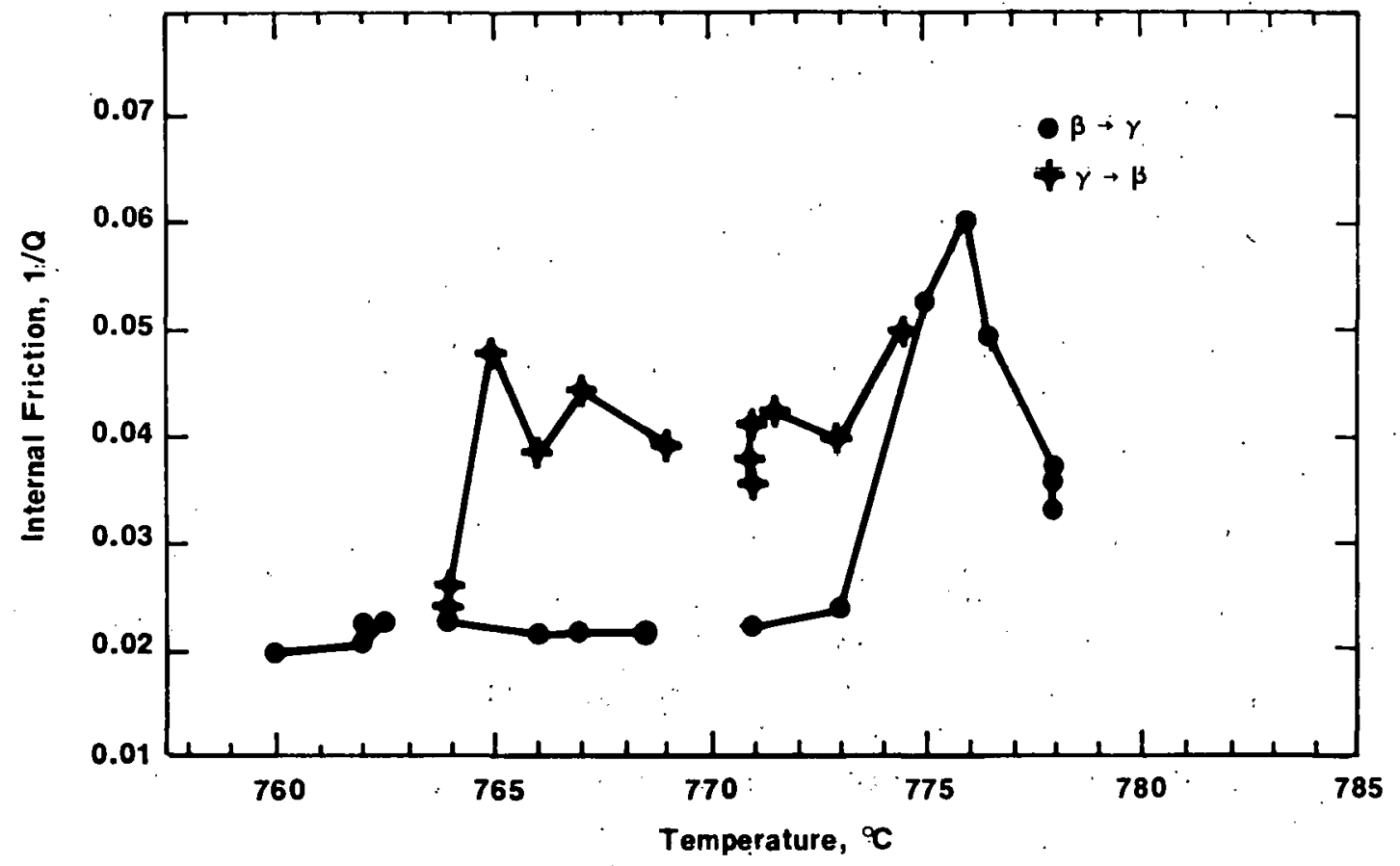

FIGURE 6 - Dynamic internal frlction values measured during isothermal transformation of the $\beta+\alpha$ and $\alpha \rightarrow \beta$ transformations of uranium. 


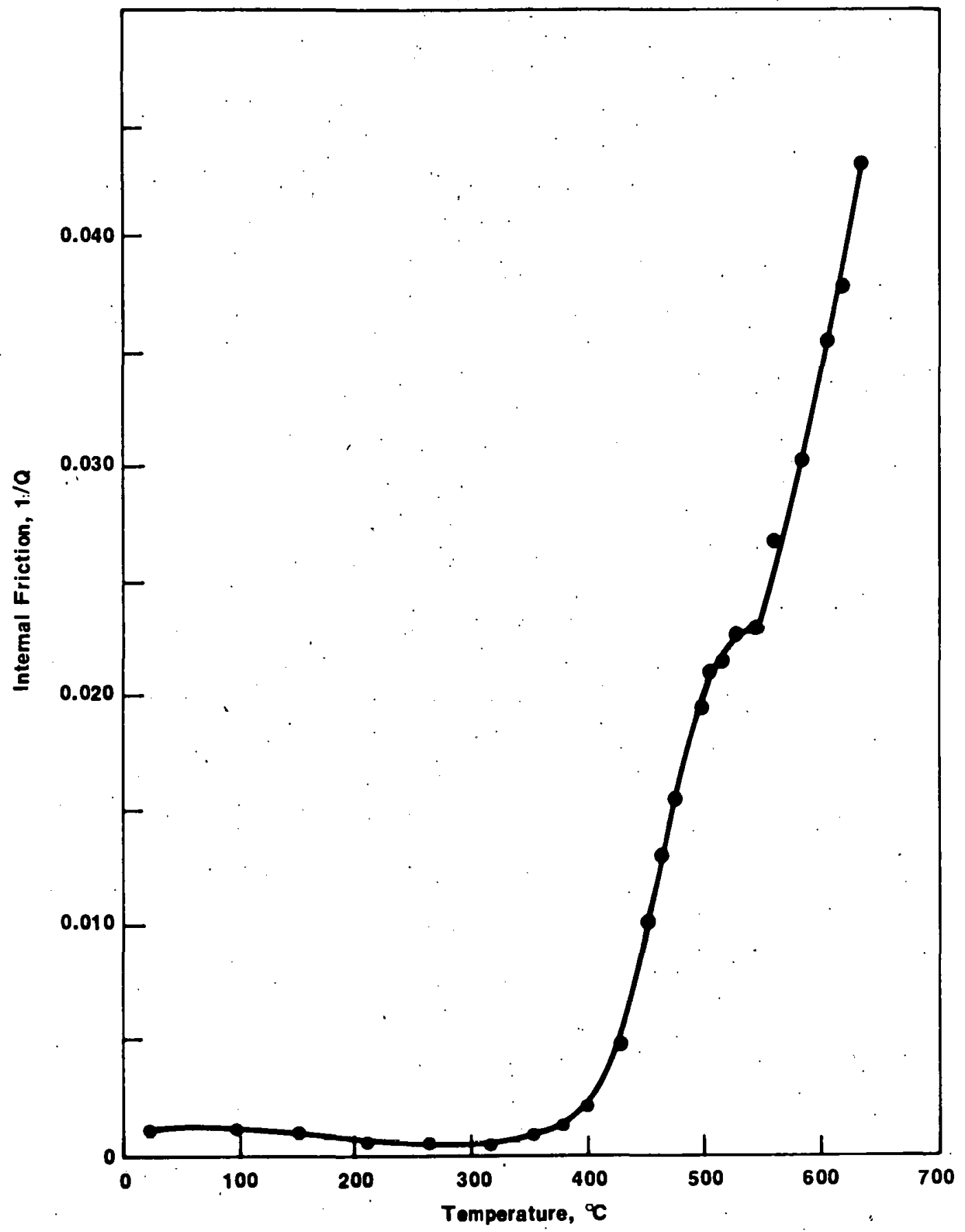

FIGURE 7 - Internal friction of $\alpha$-uranium as a function of temperature. Room temperature frequency $=2.90 \mathrm{~Hz}$. 


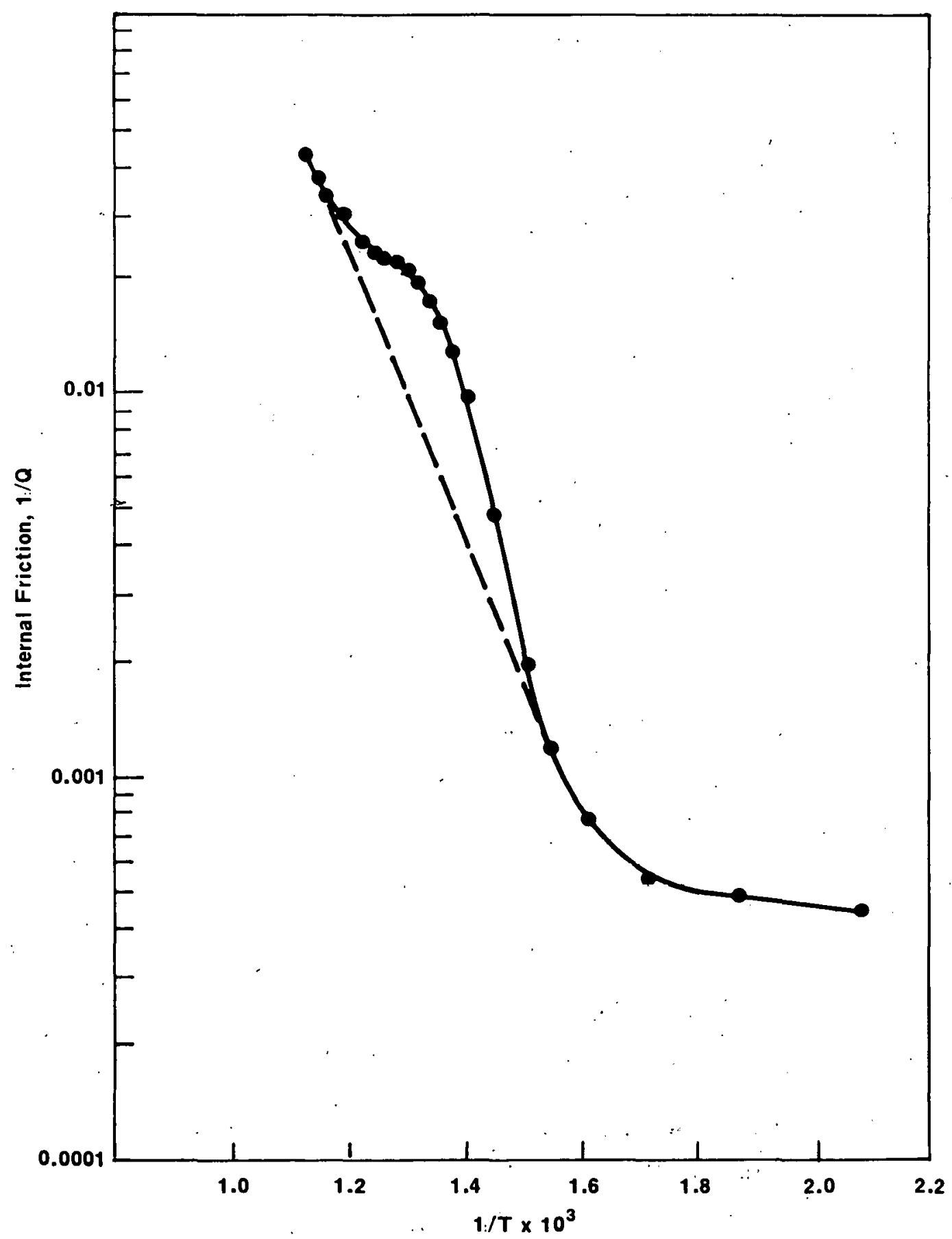

FIGURE 8 - Logarithm of internal friction as a function of reciprocal temperature. The background internal friction is indicated.by the dotted 1 ine. Room temperature frequency = $2.90 \mathrm{~Hz}$. 


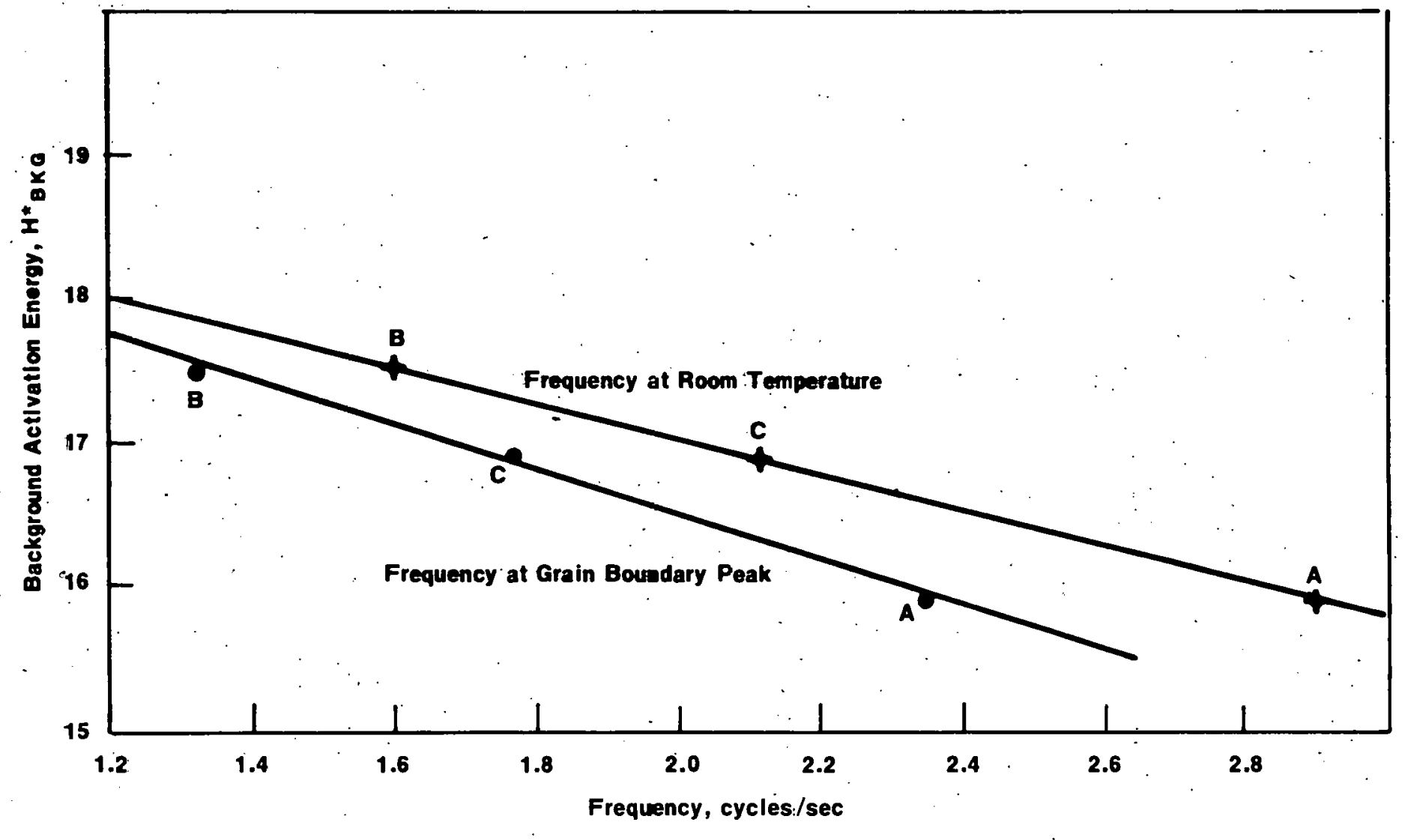

- FIGURE 9 - Background activation energy as a function of frequency. 
a straight line, as shown in Figure 10. These relationships indicate that the background internal friction is directly related to the grain boundaries.

\section{GRAIN BOUNDARY RELAXATION}

After the background internal friction is subtracted from the total, a peak is obtained as shown in Figure 11. The cause of the irregularities at higher temperature is unknown. Since they were inconsistent from one run to another, it appears that the annealing times were insufficient to obtain equilibrium results. The activation energy calculated from determinations $A, B$, and $C$ is $63.6 \mathrm{kcal} / \mathrm{mole}$. Normally, the activation energy for grain boundary relaxation would be expected to approximate that for grain boundary self-diffusion. For polycrystalline $\alpha$-uranium, this. value was found to be $40 \pm 4 \mathrm{kcal} / \mathrm{mole},{ }^{8}$ whereas for single crystal $\alpha$-uranium, it is reported to be $67 \mathrm{kcal} / \mathrm{mole} .^{9}$ The high value of 63.6 $\mathrm{kcal} / \mathrm{mole}$ for grain boundary relaxation appears anomalously high and a more detailed examination of the data appears desirable.

A method of analyzing the data has been proposed by Nowick and Berry, ${ }^{6}$ and used by Cordia and Spretnak" on several fcc metals. This analysis involves several corrections to the relaxation peak. A more detailed description of these corrections is given in the Appendix.

A summary of the calculations for the corrections to the peak location for the various determinations is given in Table 3 .

Also given are the various parameters required for these calculations including $B, \tau \mathrm{m}$, and $\Delta j$. In order to make the calculations for determinations 1 through 5, an activation energy of $63.6 \mathrm{kcal} / \mathrm{mole}$ was used for $H^{*} \mathrm{M}$. While this is not strictly correct, it is a good approximation.

A plot of the distribution parameter $\beta$ as a function of $1 / T_{P}$ is shown in Figure 12. The equation for the line for the data of determinations $A, B$, and $C$ is found to be

$$
\beta=35.70-\frac{50,600}{\mathrm{RT}}
$$

The data for determinations 1 through 5 , in general, fall above this line, but they can be used to verify the trend in the data. The negative slope of this line is rather unusual because, as pointed out by MacDonald, 10 the value of $\beta$ should decrease to zero at some critical temperature (in this case $441^{\circ} \mathrm{C}$ ) and then begin to increase again. While a value of $B=0$ means that the material behaves as a standard linear solid, this does not mean that there can be no distribution in in $\tau$. It merely means that $\tau_{0}$ and $H^{*}$ are correlated in such $a$ way that all values of $\tau$ are the same:

Calculations made from Equation (2) give the values of $\beta_{H}=50,600$ and $\beta_{0}=35.7$. The value of 50,600 for $\beta_{H}$ is very high indicating that much of the distribution in $1 n \tau$ comes from a distribution in activation energies. This suggests that impurity atoms are interfering with the basic mechanism for grain boundary relaxation. However, the value of 35.7 for $\beta_{0}$ is also high, suggesting a considerable distribution in In $\tau_{0}$. Some of the distribution in $\ln \tau$ comes from a distribution in local order and a distribution in the atomic frequency of vibration around the grain boundary. 


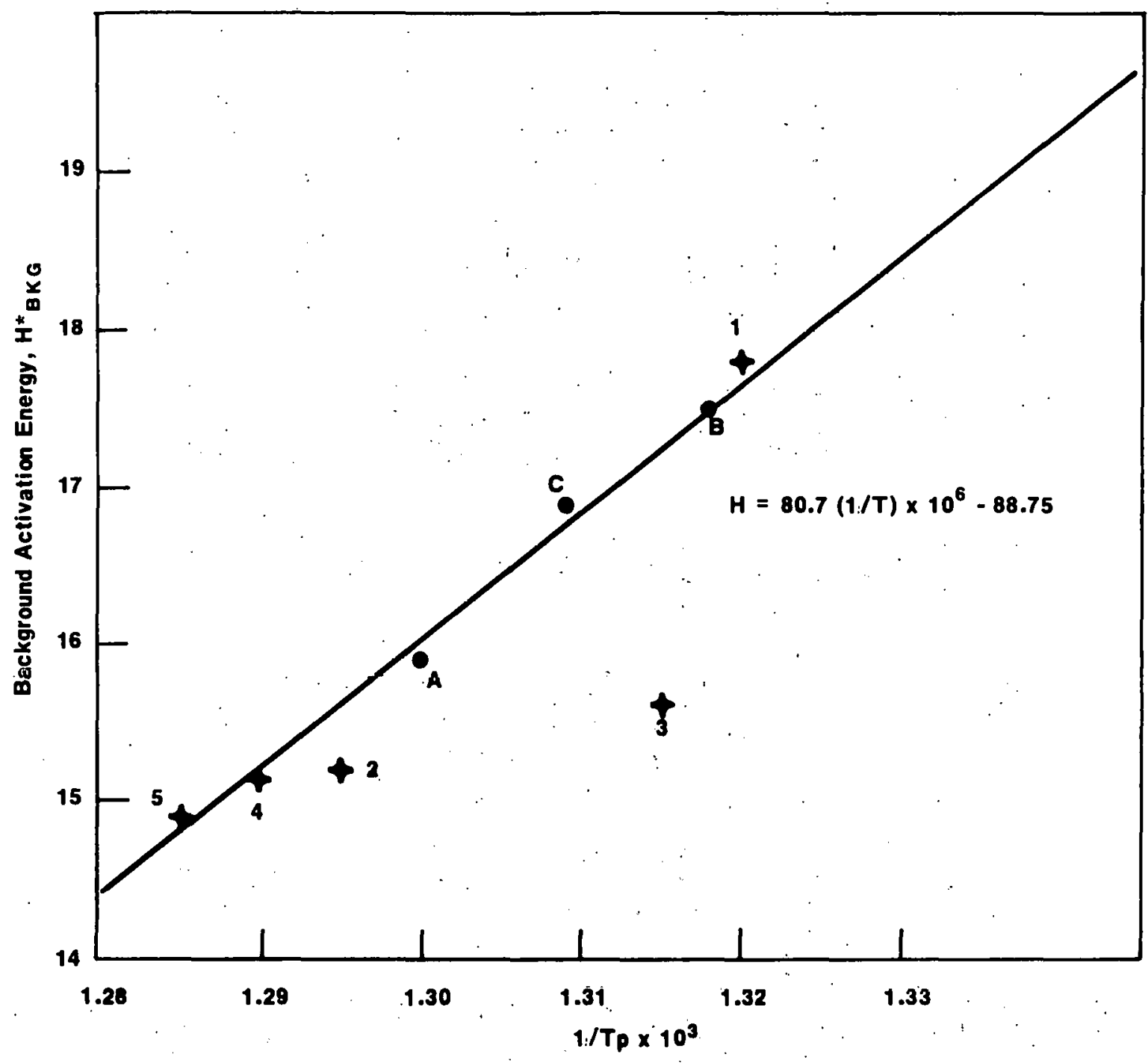

FIGURE 10 - Actiration energy for background internal friction as a function of peak temperature: 
Table 3

SUMMARY OF CALCULATIONS FOR CORRECTION FACTORS

$T \quad\left(O_{K}\right)$
$1 / T \max \times 10^{\prime} \quad$ (from
$f_{\mathrm{p}}(\mathrm{Hz})$
$1 / \mathrm{T} \quad(1 / \mathrm{T})$
$\Delta_{2} \quad$
$\mathrm{r}_{2}(\beta)$
$\beta \quad(\tan \phi)_{\max }$
$\mathrm{f}_{2}(0, \beta)$
$\Delta$
$\mathrm{h} / \mathrm{A}$
$\mathrm{A}$
$\tan \phi+\mathrm{J}_{2}$
$\delta \mathrm{J}(\mathrm{T})$
$\beta(\mathrm{T})$
$\Sigma \delta \mathrm{x}$
$\omega \tau_{\mathrm{m}}$
$\tau_{\mathrm{m}}$

\begin{tabular}{|c|c|c|c|c|c|c|c|}
\hline $\mathrm{A}$ & B & $\mathrm{C}^{\circ}$ & 1 & 2 & 3 & 4 & .5 \\
\hline 769 & 759 & 764 & 758 & 772 & 760 & 775 & 778 \\
\hline 1.300 & 1.318 & 1.309 & 1.319 & 1.295 & 1.316 & 1.290 & 1.285 \\
\hline \multirow[t]{2}{*}{2.353} & 1.325 & 1.770 & 1.172 & 2.487 & 1.158 & 1.117 & 1.177 \\
\hline & & & 1.3215 & 1.296 & 1.322 & 1.323 & 1.3215 \\
\hline 0.168 & 0.148 & 0.155 & 0.150 & 0.181 & 0.202 & 0.188 & 0.184 \\
\hline 2.04 & 1.80 & 1.88 & 1.821 & 2.20 & 2.453 & 2.282 & 2.235 \\
\hline 2.57 & 2.12 & 2.28 & 2.16 & 2.86 & 3.31 & 3.01 & 2.93 \\
\hline 0.0105 & 0.0107 & 0.0116 & 0.0195 & 0.0155 & 0.0154 & 0.0149 & 0.0088 \\
\hline 0.270 & 0.304 & 0.293 & 0.327 & 0.251 & 0.227. & 0.243 & 0.247 \\
\hline 0.040 & 0.036 & 0.040 & 0.062 & 0.064 & 0.07 .0 & 0.063 & 0.036 \\
\hline 1.000 & 0.900 & 0.095 & 0.907 & 1.062 & 1.168 & 1.099 & 1.078 \\
\hline 0.197 & 0.260 & 0.230 & 0.251 & 0.177 & 0.135 & 0.157 & 0.165 \\
\hline 0.039 & 0.032 & 0.037 & 0.054 & 0.066 & 0.079 & 0.067 & 0.038 \\
\hline 0.840 & 0.685 & 0.746 & 0.720 & 0.921 & 1.302 & 1.021 & 0.950 \\
\hline-1.023 & -0.844 & -0.908 & -0.860 & $-1,139$ & -1.318 & -1.198 & $-1,168$ \\
\hline-0.144 & -0.127 & -0.125 & -0.086 & -0.152 & -0.062 & -0.110 & -0.180 \\
\hline 0.866 & 0.881 & 0.882 & 0.918 & 0.854 & 1.065 & 0.896 & 0.835 \\
\hline 0.0587 & 0.106 & 0.079 & 0.125 & 0.0545 & 0.146 & 0.122 & 0.128 \\
\hline
\end{tabular}




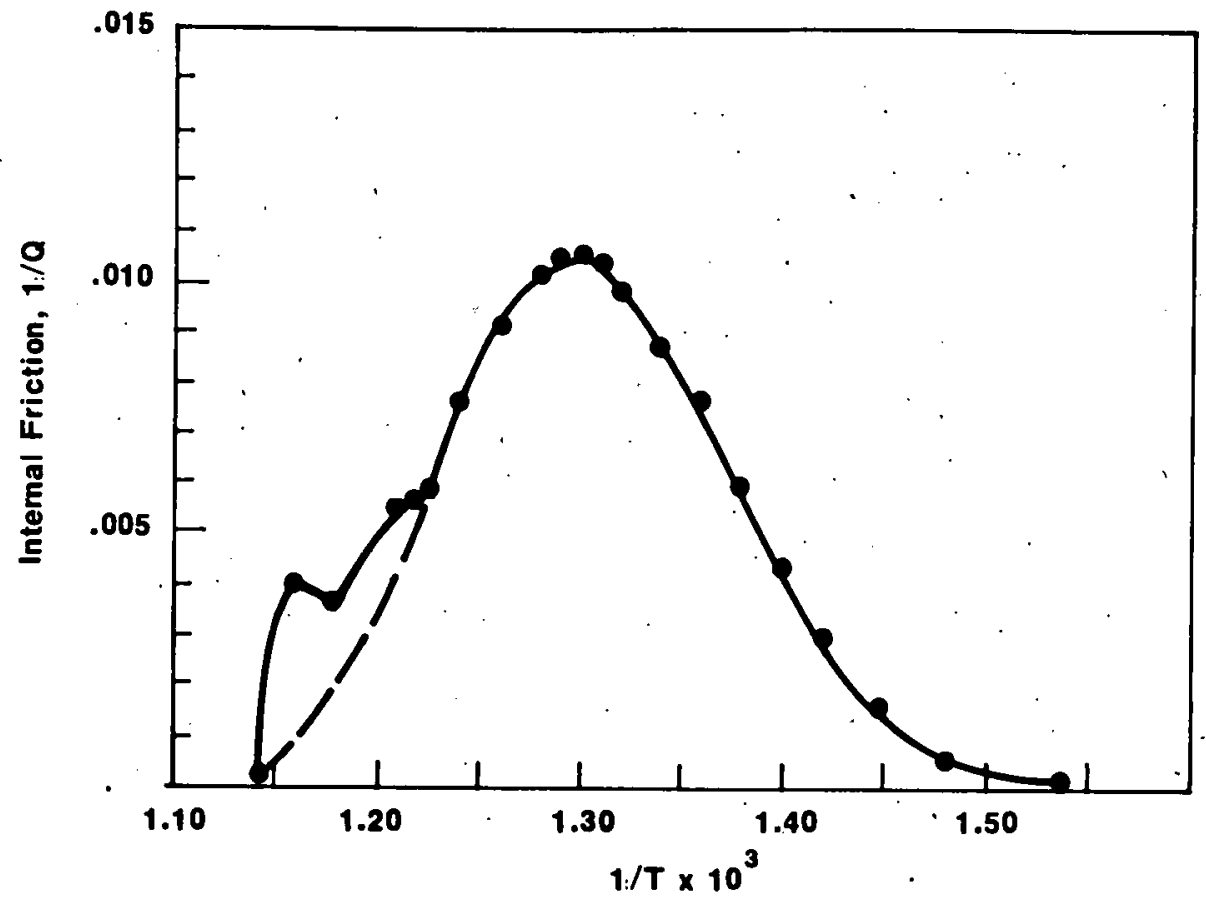

FIGURE 11 - Internal friction peak obtained after subtraction of the background.

In making the $\delta J(T)$ correction for the peak location, a value of $T=$ $658^{\circ} \mathrm{K}$ 'was used. This is equivalent to $1 / \mathrm{T}_{c}=1: 52 \times 10^{-3}$ which is the temperature at which the background internal friction begins to increase. Use of this value appears to be justified by the derivation given by Nowick and Berry. ${ }^{6}$ When the ordering energy is allowed to depend on the existing state of the order, the quantity $\mathrm{T}_{\mathrm{C}}$ is introduced into the equation. Certainly, the increase in the background internal friction is the result of a change in the order of the whole, so that the use of this value seems justifiable, particularly since there seems to be a definite correlation between $\mathrm{H}^{*} \mathrm{BK}$. and $\mathrm{T}_{\mathrm{P}}$, as shown in Figure 10 .

An interesting correlation 18 observed in connection with Figures 10 and 11. The background activation energy $H^{*} B K G$ as a function of $I / T_{P}$ appears to be independent of grain $81 z e$, whereas $\mathrm{H}_{B K G}$ as a function of frequency is very sensitive to grain size. By using Figures 9 and 10 , it is possible to "normalize" the data from determinations 1 through 5 to the grain size of A, B, and C. Starting with Figure 10 and the frequency at the peak to be normalized, a background activation energy, equivalent to the reference grain size, can be determined. Use of this value in Figure 10 gives the peak temperature referred back to the reference grain size. If this relationship holds true, the data for determinations 1 through 5 should agree with the data obtained for $A, B$, and $C$ in calculating the activation energy for the process. Figure 13 shows this to be the case. The activation energy obtained from the values of $\tau$ for $A, B$, and $C$ is $65.1 \pm 4 \mathrm{kcal} / \mathrm{mole}$, and the adjusted data for determinations 1 through 5 agree reasonably well with this line. 


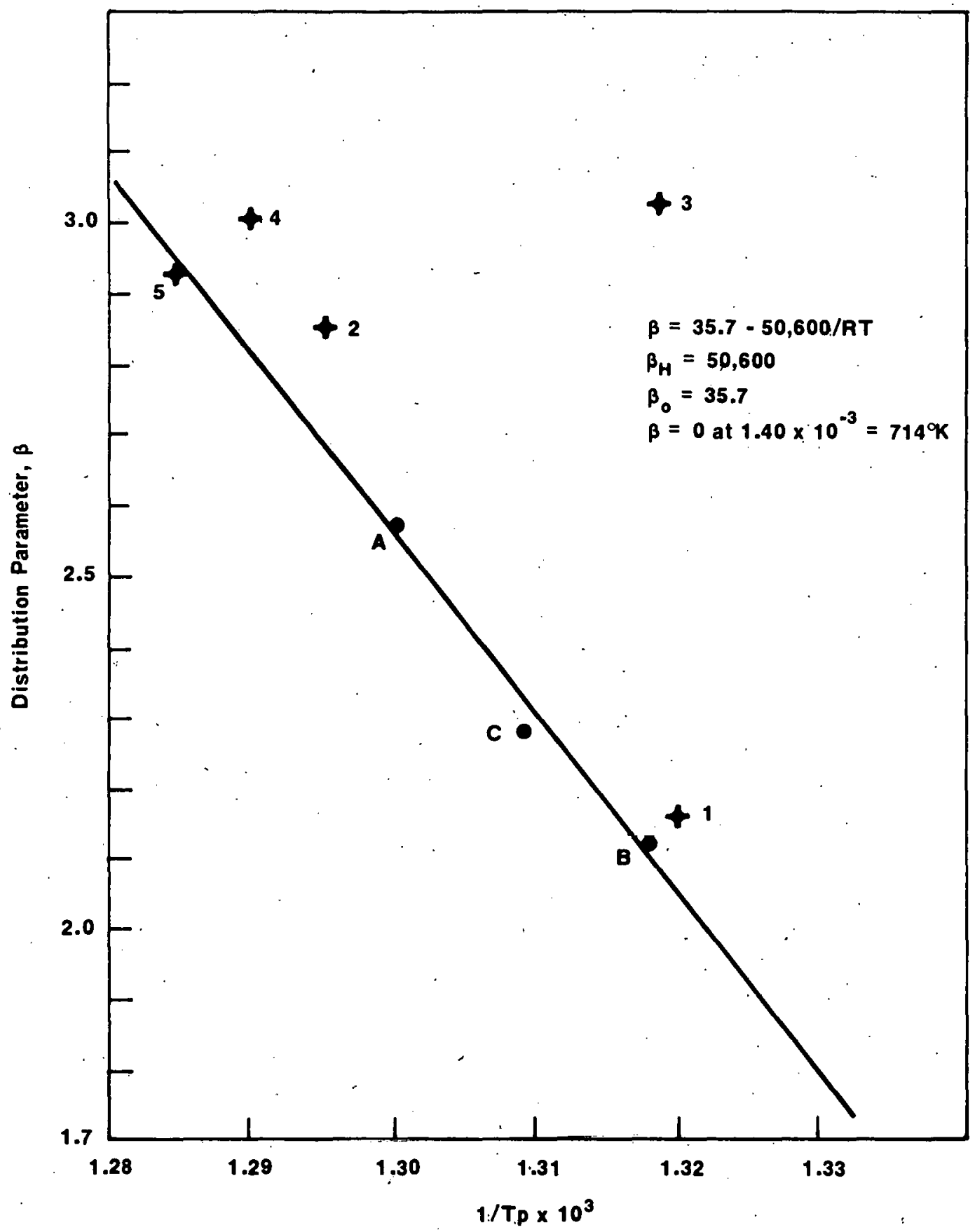

FIGURE 12 - The distrlbution parameter $\beta$ as a function of. the reciprocal of the peak temperature. 


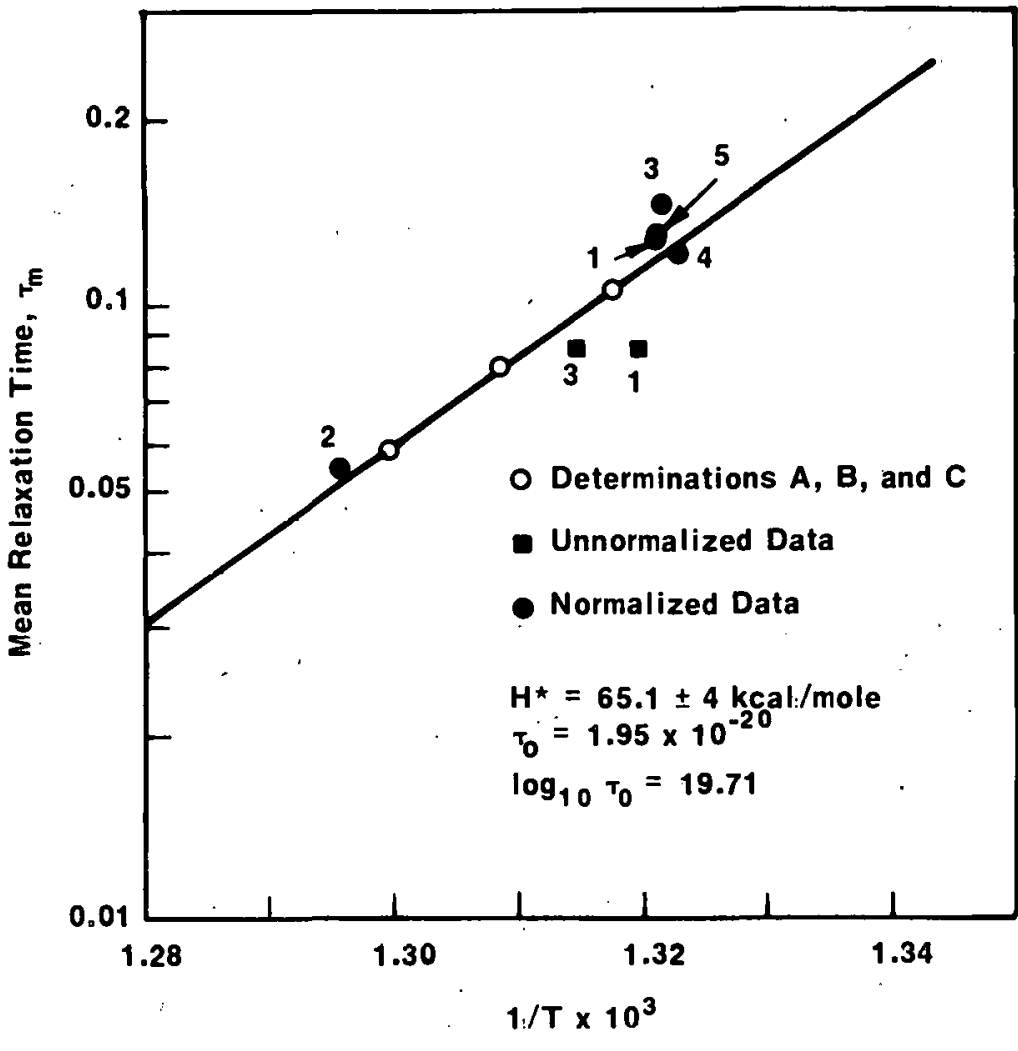

FIGURE 13 - Log $\tau$ as a function of reciprocal temperature.

\section{DISCUSSION}

\section{GENERAL FEATURES}

The higher temperature peak is apparently associated with a pretransformation phenomenon and possibly is caused by the presence of $\beta$ phase formed in the coherent boundaries during the forming process. Since there is a lattice correspondence between $\alpha$-uranium and $\beta$-uranium, ${ }^{8}$ this is possible. An applied tensile stress decreased the peak temperature suggesting that this stress promotes formation of the $B$ phase which is the least dense phase. Since the internal friction of $\beta$ is much less than that of $\alpha$, the internal friction of the sample which contains some $\beta$ phase decreases.

Earlier work ${ }^{1}$ suggested a method of determining the mechanism of transformatinn hy an analysis of the characteristics of internal friction and the relative shear modulus. From this work, the following conclusions were drawn:

1) Internal friction techniques can be used to determine the mechanisms of allotropic transformations although anelastic peaks are not obtained. 
2) Shear mechanisms are indicated when the values of internal friction above and below the transformation temperature are approximately equal and the relative shear modulus changes over a temperature range.

3) Diffusional mechanisms are indicated by a large difference between the internal friction above and below the transformation temperature and by an abrupt change in the relative shear modulus at the transformation temperature.

From the conclusions reached in the correlative study of Selle and Focke, 1 it is apparent that all of the transformations of uranium are diffusional under the heating and cooling conditions described. Isothermal transformation data shown in Figures 5 and 6 verify these conclusions. From these data, it also appears that during the active part of a transformation, the internal friction rises to a maximum and then decreases. This was also observed by Dashkovskii et al. ${ }^{4}$ This is apparently caused by the instability of the interface during transformation.

\section{BACKGROUND INTERNAL FRICTION}

The results obtained for the background internal friction are in agreement with a suggestion by Pearson, Greenough, and Smith? 1 who proposed that creep occurs at the regions of stress concentration arising from stress relaxation along the grain boundaries. If this were true, then the temperature at which the background begins to increase can be correlated to the activation energy for creep. If the line in Figure 10 is extrapolated to $1 / \mathrm{T}=1.52 \times 10^{-3}$, a value of $\mathrm{H}^{*} \mathrm{BKG}$ of $34 \mathrm{kcal} / \mathrm{mole}$ is obtained, which is in good agreement with the value of $31.2 \mathrm{kcal} / \mathrm{mole}$ obtained by Grenier, Andre, and Lacombe ${ }^{12}$ for polycrystaliine uranium. This mechanism would also account for the decrease in $H^{*}{ }_{B K G}$ as the grain size increases. Since there would be fewer regions of stress concentration, the stress level at these regions would be higher. A higher stress level increases the energy of the ground state so that less energy would be absorbed in moving the atoms to the activated state so that the activation energy would be lower. Therefore, it would appear that creep at regions of high stress concentrations is responsible for high temperature internal friction.

\section{GRAIN BOUNDARY RELAXATION}

A high degree of ordering is difficult to coincide with any picture of a grain boundary except the fit-mlsfit picture originally proposed by Mott. 12 Even then, the region of misfit must be pinned by impurity atoms. Leak ${ }^{13}$ and Miles and Leak ${ }^{14}$ have studied grain boundary relaxation in very pure iron and iron-carbon and iron-nitrogen alloys and found that the addition of small amounts of carbon and nitrogen increased the activation energy drastically. If impurity atoms segregate to the grain boundary and pinning of the misfit region results, only the region of good fit can undergo relaxation. If such a high degree of order of the boundary is envisioned, this would explain the high value for the activation energy and the high positive value for the activation entropy. 
Since the value of 35.7 for $\beta_{0}$ is high, suggesting a distribution in local order, it is desirable to determine, if possible, where some of this distribution originates. As mentioned previously, the temperature at which the background begins to increase appears to be independent of frequency and grain size. In general, the internal friction at this temperature increases with decreasing frequency. Since Figure 9 shows that the activation energy increases with decreasing frequency, a considerable variation in $17 Q_{0}$ of Equation (1) must result. This variation is shown in Figure 14.

It would be desirable if more insight could be gained into the actual mechanisms for the various processes. The high value for the activation energy suggests diffusion across areas of good fit in the boundary.

Regions of bad fit are possibly prevented from contributing to this process by impurity atoms in the grain boundary. Apparently, however, the regions of bad fit contribute to the distribution in $\ln \tau_{0}$.

\section{CONCLUSIONS}

1. Several internal friction peaks were found in $\alpha$-uranium whose magnitude changed drastically after annealing in the $\beta$ phase.

2. All of the allotropic transformations in uranium are diffusional in nature under slow heating and cooling conditions.

3. Creep at regions of high stress concentration appears to be responsible for high temperature internal friction in $\alpha$-uranium.

4. The activation energy for grain boundary relaxation in $\alpha$-uranium was found to be $65.1 \pm 4 \mathrm{kcal} / \mathrm{mole}$.

5. Impurity atoms interfere with the basic mechanism for grain boundary relaxation resulting in a distribution in activation energies.

6. A considerable distribution in $\ln \tau_{0}$ was also found which is a measure of the distribution in local order and in the. Debye frequency around a grain boundary. 


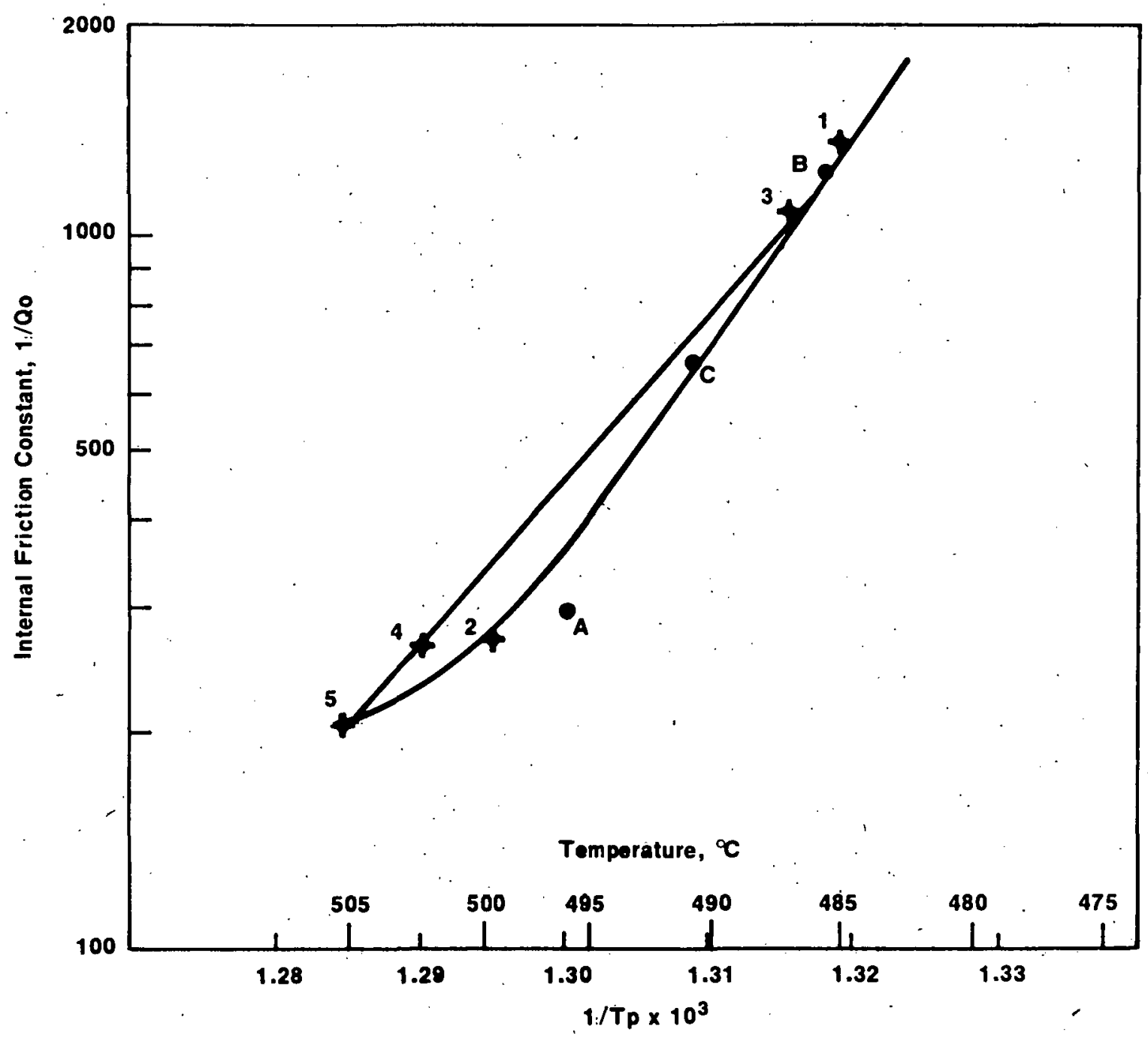

FIGURE 14 - Background internai friction constant as a function of reciprocal peak temperature. 


\section{REFERENCES}

1. J. E. Selle and A. E. Focke, "An Internal Friction Study of the Allotropic Transformation of Plutonium; Uranium and Cobalt," J. Nucl. Mater, 33, 149-158 (1969).

2. R. E. Maringer, L. L. Marsh, and G. K. Manning, "A Study of Internal Friction and Twin Boundary Movement in Uranium," BMI-1069, Battelle Memorial Institute (January 30, 1956), 33 pp.

3. R. E. Maringer, "The Effect of Changing Temperature on the Internal Friction of Uranium," BMI-X-117, Battelle Memorial Institute, 15 pp.

4. A. I. Dashkovskii, A. I. Evstyukhin, E. M. Savitskii, and D. M. Skorov, "Internal Friction in Uranium," At. Energ. 9(1), 27 (1960).

5. C. A. Wert, "The Metallurgical Use of Anelasticity," Modern Research Techniques in Physical Metallurgy, American Society for Metals, Cleveland, pp. 225-250 (1953).

6. A. S. Nowick and B. S. Berry, "The Zener Relaxation as a Distribution of Relaxation Times," TID-15085 (August 10, 1961), 20 pp.

7. J. N. Cordea and J. W. Spretnak, "Grain Boundary Relaxation in Four High Purity Face-Centered Cubic Metals," AFML-TR-65-116, Air Force Materials Laboratory (April 1965), 143 pp.

8. Y. Adda and A. Kirianenko, J. Nuc1. Mater., 6(1), 130 (1962).

9. A. A. Bochvar, V. G. Kuznetsova, V. S. Sergeev and F. P. Butra, At. Energiya USSR, 18,601 (1965).

10. J. R. MacDonald, Physica, 28, 485 (1962).

11. G. Pearson, G. B. Greenough, and A. D. N. Smith, Nature, 167, 1023 (1951).

12. N. F. Mott, Proc. Phys. Soc., 60, 391 (1948).

13. G. M. Leak, Proc. Phys. Soc., 78, 1520 (1961).

14. G. W. Miles and G. M. Leak, Proc.. Phys. Soc., 78, 1529 (1961). 


\section{APPENDIX}

Grain boundary relaxation results from the fact that a grain boundary cannot support a shear stress across it. Therefore, the relaxation process is intimately connected with the structure of the boundary, and studies of this phenomenon should yield information on the structure of the grain boundary.

At an internal friction peak, it has been shown that $w \tau=1$, where $\mathrm{w}$ is the angular frequency and $\tau$ is the relaxation time, so that if the frequency at the peak temperature is known, $\tau$ can be found. A plot of In $\tau$ as a function of $1 / \mathrm{T}$ for various frequencies should give a straight line whose slope is $H^{*} / R$ where $H^{*}$ is the activation energy and $R$ is the gas constant, and whose intercept is $\tau_{0}$, a time constant. An Arrhenius type relationship of the form

$$
\tau=\tau_{0} \exp \frac{\mathrm{H}^{*}}{\mathrm{RT}}
$$

then results.

In an idealized situation, if the internal friction is plotted as a function of $1 / T$, the width of the peak at half maximum is:

$$
\Delta\left(\frac{1}{\mathrm{~T}}\right)=2.635 \frac{\mathrm{R}}{\mathrm{H}^{\star}}
$$

where $R$ is the gas constant and $H^{*}$ is the activation energy for the process involved.

However, the idealized situation represented by Equation (A-2) is not found in grain boundary relaxation. This was first shown by $\mathrm{Ke}^{\mathrm{l}}$ and discussed by Nowick. ${ }^{2}$ The idealized case corresponds to a situation in which the relaxing interfaces are of the same size. Actually, there will be a considerable variation in the dimensions of the interfaces, and, as a result, damping measurements can no longer be described in terms of a single time of relaxation. A distribution in relaxation time results and the width of the internal friction peak is broadened to several times the width given by Equation A-2.

In order to extract as much information as possible from the data, Nowick and Berry ${ }^{3}$ have proposed an analysis which offers the possibility of obtaining more information concerning the most probable relaxation time and the mechanisms responsible for the distribution of relaxation times. A relaxation process which exhibits a Gaussian distribution of relaxation times (lognormal distribution) can be described by three parameters: the most probable relaxation time, $\tau_{m}$; the width of the distribution (distribution parameter), $B$; and the relaxation strength, $\Delta j$. The relationship between these parameters and the experimentally measured quantities are quite complicated, but Nowick and Berry have made computations which can be used.

The distribution parameter, $\beta$, can be expressed in terms of the widths of the distribution of the activation energies and of the attempt frequency, $\tau_{0}$. Equation $\mathrm{A}-1$ can be rewritten 


$$
\ln \tau=\ln \tau_{0^{\prime}}+\frac{H^{\star}}{\mathrm{RT}}
$$

From this equation, it can be seen that a distribution in $\ln \tau$ can result from a distribution in $\ln \tau_{0}$, a distribution in $H^{*}$, or both. If In $\tau_{0}$ and $H^{*}$ do not vary independently, the relationship

$$
B=\beta_{0} \pm \frac{\beta_{h i}}{R T}
$$

can be obtained; where $\beta_{h}$ is the distribution parameter for the activation energies and $B_{0}$ is the distribution parameter for in $\tau$. A plot of $\beta$ as a function of $1 / T$ should give a stralght line with the slope equal to $B h / R$ and the intercept equal to $B_{O}$.

Calculation of the most probable relaxation time, $\tau_{m}$, involves several corrections to the peak location, $x=\log w \tau_{m} \cdot$. When the change, $\delta x$, in the peak location is zero, $x=0$ and $w \tau_{m}=1$. A perturbation of the symmetric peak function serves to shift the peak location and must be taken into account. Nowick and Berry ${ }^{3}$ have given a detailed description of the corrections necessary and of the procedures for calculating them. Table A-1 gives a summary of the corrections used in this analysis.

In order to calculate the distribution parameter $\beta$, it is first necessary to calculate the relative peak width $r_{2}(B)$ by means of the equation:

$$
r_{2}(B)=\frac{H_{m} *}{2.635 R} \cdot \Delta \frac{1}{T}
$$

where $\mathrm{H}_{\mathrm{m}}$ is the mean activation energy for the relaxation process. Computations for $r_{2}(\beta)$ as a function of $\beta$ have been performed, so that by measuring the peak width at half maximum, $\Delta 1 / \mathrm{T}, \beta$ can be found.

The remaining parameter, the relaxation strength $\Delta j$, is calculated from the expression

$$
(\tan \phi) \max =F_{2}(0, \beta) \cdot \frac{\Delta j}{I+I / 2 \Delta j}
$$

where $F_{2}(O, B)$ is the relative peak height, which is also determined from the relative peak width, and ( $\tan \phi)$ max is the actual peak height.

\section{Table A-1}

CORRECTIONS TO THE LOCATION OF THE $\mathrm{J}_{2}$ : PEAK

$\frac{\text { Correction }}{\tan \phi+J_{2} \text { Conversion }}$
$\delta J(T)$
$B(T)$

$$
\begin{aligned}
& \frac{\text { Peak Location }}{\delta \mathbf{x}=\frac{h}{\mathrm{~A}} \frac{\Delta j}{1+\frac{\Delta j}{2}}} \\
& \delta \mathbf{x}=\frac{R T_{\mathrm{p}}}{\mathrm{AH}_{\mathrm{m}}} \frac{1}{1-\frac{\mathrm{T}_{\mathrm{c}}}{\mathrm{T}_{\mathrm{p}}}} \\
& \delta \mathbf{x}=-\frac{\beta_{\mathrm{o}} \beta_{\mathrm{h}}}{2 \mathrm{H}_{\mathrm{m}}}
\end{aligned}
$$




\section{REFERENCES}

1. T. S. Ke, Physical Review, 71,533 (1947).

2. A. S. Nowick, "Stress Relaxation Across Interfaces," Metal Interfaces - A Seminar, Am. Soc. Metals, Cleveland, Ohio (1951), pp. $248-$ 268. CA 46:8430f

3. A. S. Nowick and B. S. Berry, "The Zener Relaxation as a Distribution of Relaxation Times," TID-15085 (August 10, 1961), 20 pp. 
DISTRIBUTION

\section{EXTERAAL}

TID-4500, UC-25 (194)

Consultants

C. F. Curtiss

University of Wisconsin

C. F. Eck Miamisburg, Ohio

H. W. Mattson Monsanto Company

D. F. Griffing Miami University

R. E. Miers

Ft. Wayne, Indiana

G. W. Powe11

Ohio State University

A. Shapiro

University of Cincinnati

H. F. Swift

University of Dayton Research Institute

D. White

University of Pennyslvania

J. E. Selle, ORNL

H. K. Nason, MRC

INTERNÁL
W. T. Cave
R. K. Flitcraft
L. V. Jones
D. P. Kelly
B. R. Kokenge
R. E. Vallée
L. J. Wittenberg
Publications
Library (.15) 